\title{
ЭФФЕКТИВНОСТЬ МОНОТЕРАПИИ ТЕЛМИСАРТАНА ПРИ АРТЕРИАЛЬНОЙ ГИПЕРТЕНЗИИ И ХРОНИЧЕСКОЙ ОБСТРУКТИВНОЙ БОЛЕЗНИ ЛЕГКИХ
}

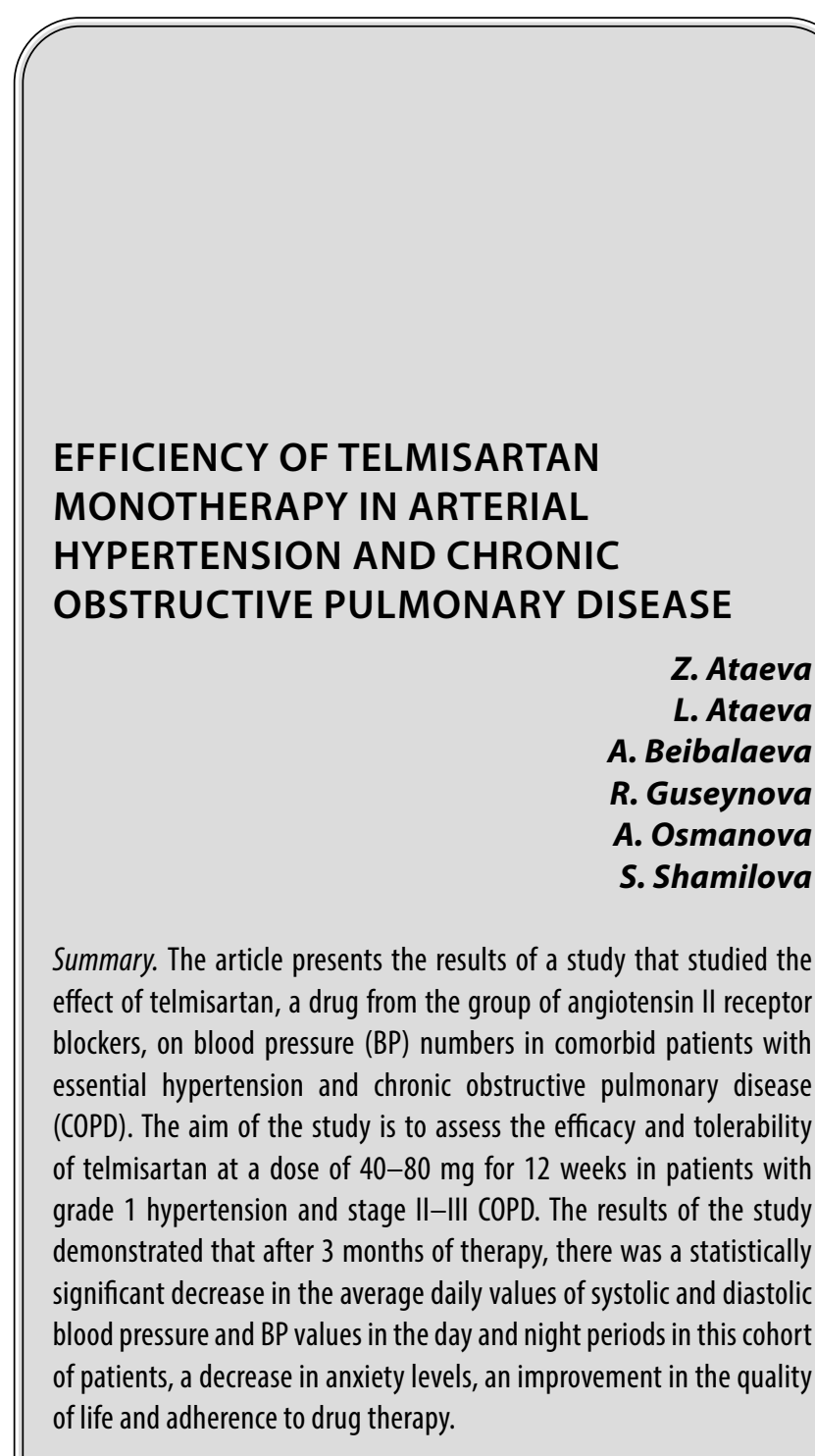

Keywords: telmisartan, arterial hypertension, chronic obstructive pulmonary disease, cardiovascular disease.
Атаева Зульмира Наримановна

К.м.н, дочент, Дагестанский государственный медицинский университет, Махачкала kzn1957@mail.ru

Атаева Лейла Алевдиновна

Дагестанский государственный медицинский университет

leyla.ataeva1988@gmail.com

Бейбалаева Амина Мусаибовна

Ассистент, Дагестанский государственный медицинский университет, Махачкала

Гусейнова Резеда Камильевна

К.м.н., дочент, Дагестанский государственный медицинский университет, Махачкала

Crezeda600512@mail.ru

Османова Аида Вахаевна

К.м.н., доцент, Дагестанский государственный медицинский университет, Махачкала aida_osmanova_1907@mail.ru

Шамилова Сабина Гаджимагомедовна

К.м.н., ассистент, Дагестанский государственный медицинский университет, Махачкала

Sabina.shamilova.84@mail.ru

Аннотация. В статье представлены результаты исследования, в котором изучалось влияние препарата из группы блокаторов рецепторов ангиотензина II типа телмисартана на цифры артериального давления (АД) у коморбидных пациентов с гипертонической болезнью и хронической обструктивной болезнью легких (ХОБЛ).

Цель исследования - оценка эффективности и переносимости телмисартана в дозе 40-80 мг в течение 12 недель у пациентов с АГ 1-й степени и ХОБЛ II-III стадии. Результаты исследования показали, что на фоне терапии через 3 месяца произошло статистически значимое снижение среднесуточных цифр систолического и диастолического АД и показателей АД В дневной и ночной периоды у этой когорты пациентов, снижение уровня тревоги, улучшение качества жизни и приверженности к медикаментозной терапии.

Ключевые слова: телмисартан, артериальная гипертония, хроническая обструктивная болезнь легких, сердечно — сосудистые заболевания. 
Таблица 1. Клиническая характеристика пациентов

\begin{tabular}{|c|c|}
\hline Параметр & $\mathrm{N}=\mathbf{3 0}$ \\
\hline Возраст & $58,3 \pm 4,5$ \\
\hline Мужской пол, n (\%) & $7(23,3 \%)$ \\
\hline Длительность АГ, лет & $5,2 \pm 2,3$ \\
\hline Индекс массы тела, кг/м² & $28,8 \pm 1,8$ \\
\hline Курение, n (\%) & $8(26,7 \%)$ \\
\hline Сахарный диабет 2-го типа, n(\%) & $3(10 \%)$ \\
\hline Предшествующая антигипертензивная терапия, n (\%) & $6(20 \%)$ \\
\hline
\end{tabular}

\section{Введение}

A ртериальная гипертония (АГ) представляет собой один из ключевых факторов риска развития сердечно-сосудистых заболеваний (СС3) и является основным модифицируемым фактором риска ряда СС3 и смерти от всех причин во всем мире.

Несмотря на все новые достижения в лабораторно-инструментальной диагностике, в лечении АГ все еще сохраняются проблемы комплексного подхода к терапии таких пациентов с хронической обструктивной болезнью легких (ХОБЛ) $[1,2,3]$

Увеличение числа больных с сочетанием АГ и бронхообструктивных заболеваний обусловлено как повышением заболеваемости АГ и ХОБЛ, так и увеличением популяции больных пожилого и старческого возрастов. По данным разных авторов, АГ развивается у 49,6$63,4 \%$ больных ХОБЛ $[4,5,6$.$] .$

Выбор антигипертензивного препарата у пациентов, страдающих ХОБЛ, может вызвать трудности, так как лекарственный препарат потенциально способен спровоцировать бронхиальную обструкцию, вазоконстрикцию в малом круге кровообращения, усиливать кашель, вступать в антагонистические отношения с бронходилататорами.[7]

Так, назначение ингибиторов ангиотензинпревращающего фермента (ИАПФ) может спровоцировать появление брадикининового кашля, имитирующего обострение ХОБЛ, и приводить к неоправданному усилению бронходилатирующей терапии, что, в свою очередь, способствует усугублению течения АГ [8]. Представители класса блокаторов рецепторов ангиотензина II (БРА) относятся к препаратам выбора для пациентов с АГ и ХОБЛ, поскольку они увеличивают продукцию оксида азота, улучшают функцию эндотелия [9] и снижают давление легочной артерии [10] и не вызывают появления брадикининового кашля. Одним из наиболее представительных препаратов из группы БРА является телмисартан.

\section{Цель исслеАования}

Оценка эффективности и переносимости антагониста рецепторов ангиотензина II - телмисартана («Телзап», Санофи, Франция) в дозе 40-80 мг в сутки у больных АГ 1-й степени и хронической обструктивной болезнью легких (ХОБЛ) II-III стадии.

\section{Материал и методы}

Обследовано 30 пациентов с ХОБЛ II-III стадии (категории B и D по Gold) в период ремиссии, с нелеченной ранее АГ I степени. Средний возраст составил 54,3 4,5 года. Клиническая характеристика пациентов представлена в таблице 1.

Критерии включения: возраст больных от 40-65 лет, уровень АД в момент включения более 140/90 и меньше 160/100 мм рт.ст., длительность заболевания АГ не менее 12 месяцев.

Критерии исключения: симптоматическая АГ, нарушение мозгового кровообращения или острый коронарный синдром в течение ближайшего года, наличие хронической сердечной недостаточности II-IV классов по NYHA, декомпенсированный сахарный диабет 2 или 1 типа, атриовентрикулярные блокады II-III степени, нарушение функции почек и печени, беременность и лактация, повышенная чувствительность к препарату или его компонентам, прием пероральных стероидных препаратов более 10 дней за последние 6 месяцев, онкологические заболевания.

В течение 12 недель пациенты получали препарат «Телзап». Начальная дозировка составила 40 мг/сут. При недостаточном гипотензивном эффекте через 4 недели лечения дозу препарата увеличивали до 80 мг/сут.

Оценка безопасности применения препарата «Телзап» проводили на основании данных о побочных эффектах препарата, выявленных в процессе применения, с учетом изучения субъективных и объективных критериев. В зависимости от наличия и выраженности 
Таблица 2. Динамика параметров физикального обследования и биохимических показателей до и после лечения $(\mathrm{M} \pm \mathrm{d})$

\begin{tabular}{|c|c|c|c|c|}
\hline Показатель & \begin{tabular}{|l} 
Визит 1 \\
(исходно)
\end{tabular} & \begin{tabular}{|l} 
Визит 2 \\
(через 4 недели)
\end{tabular} & \begin{tabular}{|l} 
Визит 3 \\
(через 12 недель)
\end{tabular} & $\begin{array}{l}\text { Статистическая } \\
\text { значимость, } \mathbf{p}_{I-3}\end{array}$ \\
\hline ИMT, кг/M $\mathrm{M}^{2}$ & $28,8 \pm 1,8$ & - & $29,7 \pm 3,1$ & $>0,05$ \\
\hline OT/OБ & $0,97 \pm 0,02$ & - & $0,96 \pm 0,02$ & $>0,05$ \\
\hline ЧСС, уд/мин & $73,5 \pm 5,25$ & $73,8 \pm 4,84$ & $70,34 \pm 2,62$ & $>0,05$ \\
\hline Среднее САД, мм.рт.ст. & $149,5 \pm 10,54$ & $140,37 \pm 12,66$ & $120,15 \pm 8,45$ & 0,047 \\
\hline Среднее ДАД, мм. рт.ст. & $95,7 \pm 5,21$ & $84,09 \pm 8,3$ & $75,8 \pm 6,6$ & 0,043 \\
\hline Общий ХС, ммоль/л & $5,4 \pm 0,35$ & - & $4,8 \pm 0,76$ & $>0,05$ \\
\hline ХС ЛПНП, ммоль/л & $3,12 \pm 0,79$ & - & $3,02 \pm 0,65$ & $>0,05$ \\
\hline ХС ЛПВП, ммоль/л & $0,85 \pm 0,26$ & - & $0,97 \pm 0,35$ & $>0,05$ \\
\hline Триглицериды, ммоль/л & $2,32 \pm 1,2$ & - & $2,22 \pm 1,3$ & $>0,05$ \\
\hline Глюкоза крови, ммоль/л & $5,28 \pm 0,89$ & - & $4,71 \pm 0,54$ & $<0,01$ \\
\hline Калий крови, ммоль/л & $4,21 \pm 0,4$ & - & $4,22 \pm 0,4$ & $>0,05$ \\
\hline Креатинин крови, ммоль/л & $86,3 \pm 10,6$ & - & $85,9 \pm 10,2$ & $>0,05$ \\
\hline
\end{tabular}

ОТ - окружность талии, ОБ - окружность бедер, чСС - частота сердечных сокращений, САД систолическое АД; ДАД - диастолическое АД; ХС - холестерин; ЛПНП - липопротеиды низкой плотности; ЛПВП - липопротеиды высокой плотности.

Таблица 3. Параметры инструментальных исследований (ЭКГ, ЭхоКГ) до и после терапии телмисартаном $(\mathrm{M} \pm \mathrm{d})$

\begin{tabular}{|l|l|l|l|} 
Параметры & $\begin{array}{l}\text { Визит 1 } \\
\text { (исходно) }\end{array}$ & $\begin{array}{l}\text { Визит 3 } \\
\text { (через 12 недель) }\end{array}$ & $\begin{array}{l}\text { Статистическая значимость, } \\
\mathbf{p}\end{array}$ \\
\hline Индекс Соколова-Лайона, мм & $27,4 \pm 6,5$ & $26,5 \pm 6,3$ & $>0,05$ \\
\hline КДР ЛЖ, см & $5,24 \pm 0,25$ & $5,21 \pm 0,23$ & $>0,05$ \\
\hline ЛП, см & $3,63 \pm 0,51$ & $3,64 \pm 0,41$ & $>0,05$ \\
\hline МЖП в диастолу, см & $1,11 \pm 0,22$ & $1,12 \pm 0,21$ & $>0,05$ \\
\hline ЗСЛЖ в диастолу, см & $1,01 \pm 0,11$ & $1,09 \pm 0,18$ & $>0,05$ \\
\hline
\end{tabular}

КДР ЛЖ - конечно - диастолический размер левого желудочка, лП — левое предсердие, МЖП межжелудочковая перегородка, ЗСлЖ - задняя стенка левого желудочка

побочных эффектов выносилось заключение о переносимости препарата. Эффективность терапии контролировалась с помощью суточного мониторирования АД (СМАД). Базисная терапия ХОБЛ включала антихолинергические препараты, бета-2-адреномиметики или их комбинацию.

За время исследования (12 недель) предусматривалось проведение 3-х визитов: визит 1-включения (в течение 5 дней до визита включения пациент не получал антигипертензивную терапию). Во время 1 -го и 3-го (через 12 недель) визитов проводилось физикальное исследование, включающее определение индекса массы тела (ИМТ), индекса окружности талии/окружности бедра (ОТ/ОБ), измерение АД в положении сидя и стоя, определение частоты сердечных сокращений (ЧСС). Кроме того, на визитах 1 и 3 проведены следующие лабораторные исследования: общий анализ крови, общий анализ мочи, липидный профиль, определены уровни глюкозы крови, калия крови, креатинина крови. Из функциональных исследований проводились ЭКГ, ЧСС, вольтажные критерии гипертрофии миокарда левого желудочка (ЛЖ), суточное мониторирование АД (СМАД): средние суточные, дневные и ночные цифры АД, суточный индекс систолического АД (САД) и диастолического АД (ДАД), ЭхоКГ, комплекса интима-медиа (КИМ) сонных артерий, показатели функции внешнего дыхания: ЖЕЛ, ФЖЕЛ, ОФВ1, индекс Тиффно, оценку одышки по шкале $\mathrm{mMRC}$ и оценочный тест по ХОБЛ CAT. Во время 1 и 3 -го визитов также определены уровень тревоги по шкале Гамильтона (HARS-The Hamilton Anxiety Rating Scale), показатель качества жизни по визуально-аналоговой шкале (ВАШ), оценена приверженность терапии путем прямого вопроса о приеме исследуемого препарата и подсчета таблеток.

Статистическая обработка результатов выполнена с помощью компьютерной статистической программы 
Таблица 4. Параметры суточного мониторирования артериального давления до и после терапии телмисартаном

\begin{tabular}{|l|l|l|}
\hline Показатель & Исходно & Через 4 недели \\
\hline САД сут., мМ.рТ.СТ. & $144,7 \pm 8,13$ & $120,12 \pm 8,6^{*}$ \\
\hline ДАД сут, мм.рт.ст. & $86,35 \pm 7,16$ & $75,3 \pm 5,5^{*}$ \\
\hline САД дн., мм.рт.ст. & $149,88 \pm 8,8$ & $130,5 \pm 8,1^{*}$ \\
\hline ДАД дн., мм.рт.ст. & $90,4 \pm 8,2$ & $78,3 \pm 7,5^{*}$ \\
\hline САД н., мм.рт.ст. & $137,65 \pm 10,1$ & $110,44 \pm 12,8^{*}$ \\
\hline ДАД н., мм.рт.Ст. & $80,8 \pm 8,7$ & $69,8 \pm 6,65^{*}$ \\
\hline СИ САД,\% & $8,53 \pm 6,6$ & $8,35 \pm 6,7$ \\
\hline СИ ДАД,\% & $10,03 \pm 6,1$ & $10,8 \pm 6,02$ \\
\hline
\end{tabular}

САД сут (ДАД сут) — среднее суточное систолическое (диастолическое) АД; САД дН (ДАД дн) среднее дневное САД и ДАД; САД н (ДАД н) - среднее ночное САД и ДАД; СИ САД, СИ ДАД суточный индекс САД и ДАД. * ${ }^{*}-0,0,05$.

Таблица 5. Динамика показателей уровня тревоги, качества жизни и приверженности к лечению $(\mathrm{M} \pm \mathrm{d})$

\begin{tabular}{|l|l|l|l|l|}
\hline Параметры & Визит 1 & Визит 2 & Визит 3 & Статистическая значимость, $\mathbf{p}_{l-3}$ \\
\hline HARS, баллы & $7,42 \pm 2,1$ & - & $5,1 \pm 1,34$ & $\mathrm{p}<0,05$ \\
\hline Качество жизни, баллы & $42,2 \pm 7,6$ & - & $69,3 \pm 8,32$ & $\mathrm{p}<0,05$ \\
\hline Приверженность терапии,\% & - & $96,9 \pm 4,23$ & $99,8 \pm 0,31$ & $\mathrm{p}<0,05$ \\
\hline
\end{tabular}

Statistica 6.0 с использованием t- критерия Стьюдента и критерия Манна-Уитни.

\section{Результаты и их обсужление}

Динамика данных физикального обследования и биохимических показателей представлена в таблице 2.

Как видно из таблицы 2 значения ИМТ, ОТ/ОБ, ЧСС, показатели липидного обмена, уровни калия и креатинина крови не имели статистически значимой динамики, однако отмечена стойкая тенденция улучшения этих параметров. Динамика показателей АД, а также уровня глюкозы крови, напротив, была достоверной.

Изменения показателей инструментальных исследований представлены в таблице 3

Как видно из таблицы 3, через три месяца назначения гипотензивной терапии изменения показателей ЭКГ и ЭхоКГ не имели статистической значимости, что можно объяснить малым сроком исследования. В 90\% случаев было выявлено увеличение КИМ, у 34,2\% пациентов обнаружены атеросклеротические бляшки различной локализации. На фоне проводимой терапии статистически значимой динамики этих показателей не наблюдали.
Параметры СМАД до и после лечения представлены в таблице 4.

Как видно из данных, представленных в таблице 4, под влиянием назначенной терапии произошло статистически значимое снижение как среднесуточных показателей САД и ДАД, так и показателей АД в дневной и ночной период. При анализе суточного профиля АД до терапии преобладали пациенты с повышением или отсутствием снижения АД в ночном периоде. Во время терапии увеличилось количество пациентов с физиологическим ночным снижением АД до 62\%. Все больные по данным СМАД на фоне лечения достигли целевых цифр АД. Увеличение дозы до 80 мг в сутки потребовалось у $60 \%$ пациентов. В этой связи следует отметить, что в последних рекомендациях по диагностике и лечению АГ от 2018 года приветствуется более широко использовать СМАД наряду с домашним мониторированием АД с целью не только диагностики, но и контроля АГ [11]. СМАД обладает более высокой предсказательной ценностью в отношении поражения органов-мишеней, чем клиническое (офисное) измерение АД [12], является более чувствительным, чем офисное АД, и результаты измерения АД, полученные при СМАД, считаются лучшим предиктором коронарных событий, инсульта и фатальных исходов $[13,14,15,16,17]$. 
Динамика показателей уровня тревоги, качества жизни и приверженности терапии представлена в таблице 5.

Как видно из таблицы 5, отмечена статистически значимая положительная динамика показателей уровня тревоги и качества жизни и приверженности к терапии.

На фоне лечения данные спирометрии (ЖЕЛ, ФЖЕЛ, ОФВ1, индекс Тиффно) оценки одышки по шкале $\mathrm{mMRC}$ и оценочного теста по ХОБЛ -САТ достоверно не изменились.

За время исследования у 4 пациентов (13,3\%) наблюдались побочные эффекты, характерные для приема препаратов данного класса: повышенная утомляемость, общая слабость. Все явления были кратковременными и не потребовали отмены препарата.

\section{Bыво}

Представитель класса БРА телмисартан (Телзап) продемонстрировал высокую антигипертензивную эффективность, метаболическую нейтральность и безопасность у больных АГ І степени в сочетании с ХОБЛ II-III стадии по Gold. На фоне терапии не наблюдалось усугубление гипоксии и выявлена статистически значимая нормализация показателей СМАД с коррекцией патологических типов суточных кривых АД в ночной период.

\section{ЛИТЕРАТУРА}

1. Chow C.K., Teo K.K., Rangarajan S. et al. PURE Study Investigators. Prevalence, awareness, treatment, and control of hypertension in rural and urban communities in high-, middle-, and low-income countries. JAMA. 2013; 310: 959-968.

2. Falaschetti E., Mindell J., Knott C., Poulter N. Hypertension management in England: a serial cross-sectional study from 1994 to 2011. Lancet. 2014; 383: 1912-1919.

3. Tocci G., Rosei E.A., Ambrosioni E. et al. Blood pressure control in Italy: analysis of clinical data from 2005-2011 surveys on hypertension. J Hypertens. 2012; 30: 1065-10744.

4. Almagro P., Cabrera F.J., Diez J., Boixeda R., Alonso Ortiz M.B., Murio C. et al. Comorbidities and short-term prognosis in patients hospitalized for acute exacerbation of COPD. The ESMI study. Chest. 2012; 142(5): 1126-1133.

5. Park H.J., Leem A.Y., Lee S.H., Song J.H., Park M.S., Kim Y.S. et al. Comorbidities in obstructive lung disease in Korea: data from the fourth and fifth Korean National Health and Nutrition Examination Survey. Int. J. Chron. Obstruct. Pulmon. Dis. 2015; 10: 1571-1582.

6. Hillas G., Perlikos F., Tsiligianni I., Tzanakis N. Managing comorbidities in COPD. Int J Chron Obstruct Pulmon Dis. 2015; 10: 95-109.

7. Гуревич М.А., Долгова Е.В., Кузьменко Н.А. Хронические обструктивные заболевания легких, артериальная гипертензия и ишемическая болезнь сердца: особенности патогенеза, клинической картины, терапии. РМЖ. 2016; 16: 1098-1102.

8. Yusuf S., Teo K.K., Pogue J., Dyal L., Copland I et al. Telmisartan, ramipril, or both in patients at high risk for vascular events. ONTARGET Investigators. N Engl J Med. 2008; 358 (15): 1547-59.

9. Kronish I.M., Woodward M., Sergie Z. et al. Meta-analysis: impact of drug class on adherence to antihypertensives. Circulation. 2011; 123: 1611-1621

10. Hung K.F., Adcock I.M. Multifaceted mechanisms in COPD: inflammation, immunity, and tissue repair and destruction. EurRespir J. 2008; 31(6): $1334-1356$.

11. Williams B., Mancia G., Spiering W. et al. 2018 ESC/ESH Guidelines for the management of arterial hypertension. Eur Heart J. $2018 ; 39$ (33): $3021-3104$.

12. Gaborieau V., Delarche N., Gosse P. Ambulatory blood pressure monitoring versus self-measurement of blood pressure at home: correlation with target organ damage. J Hypertens. 2008; 26: 1919-1927.

13. Banegas J.R., Ruilope L.M., de la Sierra A. et al. Relationship between clinic and ambulatory blood-pressure measurements and mortality. N Engl J Med 2018; 378: $1509-1520$.

14. Investigators A.B.C. - H., Roush G.C. et al. Prognostic impact from clinic, daytime, and night-time systolic blood pressure in nine cohorts of 13,844 patients with hypertension. J Hypertens. 2014; 32: 2332-2340.

15. Fagard R.H., Celis H., Thijs L. et al. Daytime and nighttime blood pressure as predictors of death and cause-specific cardiovascular events in hypertension. Hypertension. 2008; 51: 55-61.

16. Parati G., Ochoa J.E., Bilo G. et al. European Renal and Cardiovascular Medicine Working Group of the European Renal Association-European Dialysis and Transplant Association. Hypertension in chronic kidney disease part 2: role of ambulatory and home blood pressure monitoring for assessing alterations in blood pressure variability and blood pressure profiles. Hypertension 2016; 67: 1102-1110.

17. Piper M.A., Evans C.V., Burda B.U. et al. Diagnostic and predictive accuracy of blood pressure screening methods with consideration of rescreening intervals: a systematic review for the U.S. Preventive Services Task Force. Ann Intern Med. 2015;162:192-204. 